\title{
PENGARUH METODE RANDOM DAN METODE BLOCKED TERHADAP KEMAMPUAN PASSING HIT DALAM PERMAINAN HOKI
}

\author{
Aziz Amrulloh ${ }^{1}$ \\ Program Studi Pendidikan Jasmani Kesehatan dan Rekreasi, \\ Fakultas Kegruruan dan Ilmu Pendidikan, Universitas \\ Suryakancana, \\ Aziz_amrulloh@yahoo.com
}

\begin{tabular}{ll}
\hline Info Artikel & Abstrak \\
\hline Sejarah Artikel: & Penelitian ini bertujuan untuk mengetahui pengaruh metode \\
Diterima Maret 2019 & random dan metode blocked terhadap kemampuan passing hit. \\
Disetujui April 2019 & Penelitian ini mengunakan metode eksperimen dengan desain \\
Dipublikasikan Juni 2019 & "true eksperimental control pretest-posttest design". Populasi \\
& dalam penelitian ini adalah seluruh atlet hoki remaja Kabupaten \\
& Cianjur. Teknik sampling dari populasi ke sampel \\
& menggunakan teknik sampling total/sampling jenuh. Sampel \\
& dalam penelitian ini berjumlah 30 orang atlet remaja Kabupaten \\
& Cianjur. Instrumen yang digunakan adalah Tes Keterampilan \\
& Hit. Analisis data menggunakan SPSS versi 22 pada taraf \\
& signifikansi $\alpha=0,05$. Hasil analisis menunjukkan bahwa \\
& (1)Terdapat pengaruh yang signifikan metode random terhadap \\
& kemampuan passing hit dalam permainan hoki atlet remaja \\
& Cianjur. (2)Terdapat pengaruh yang signifikan metode blocked \\
& terhadap kemampuan passing hit dalam permainan hoki atlet \\
& remaja Cianjur. (3) Metode blocked lebih signifikan \\
pengaruhnya dibandingkan metode random terhadap & kemampuan passing hit dalam permainan hoki atlet remaja \\
& Cianjur.
\end{tabular}

Keyword:

Pengaruh, Metode

Random, Blocked,

Abstrack

Kemampuan Passing Hit

This study aims to determine the effect of the random method and the blocked method on the ability to pass hits. This study uses an experimental method with the design of "true experimental control pretest-posttest design". The population in this study were all teenage hockey athletes in Cianjur Regency. The sampling technique from population to sample uses a total sampling technique / saturated sampling. The sample in this study amounted to 30 youth athletes in Cianjur Regency. The instrument used was the Hit Skill Test. Data analysis using SPSS version 22 at the significance level $\alpha=$ 0.05. The results of the analysis showed that (1) There was a significant influence of the random method on the ability of passing hits in the Cianjur teen athlete hockey game. (2) There is a significant effect of blocked method on passing hit ability in Cianjur teen athlete hockey games. (3) The blocked method has more significant influence than the random method on the passing hit ability in the Cianjur teen athlete hockey game

(C) 2019 Universitas Suryakancana 


\section{8 | Aziz Amrulloh ${ }^{1}$}

Pengaruh Metode Random Dan Metode Blocked Terhadap

Kemampuan Passing Hit Dalam Permainan Hoki

\section{A. PENDAHULUAN}

Hoki merupakan salah satu cabang olahraga permainan beregu, dimana setiap pemain menggunakan alat yang disebut stik untuk menahan, membawa dan memukul bola sesuai dengan peraturan permainan yang telah di tetapkan, olahraga ini di mainkan oleh dua regu yang berusaha memasukkan bola kegawang lawan. Olahraga hoki dapat di mainkan dalam ruangan (indoor) dan di lapangan terbuka (field). Dalam permainan hoki ruangan mempunyai peraturan tersendiri yang sebagian tidak sama dengan permainan hoki lapangan. 
Perbedaan permainan tersebut dapat dilihat dari jumlah pemain, dalam hoki ruangan tiap tim terdiri dari 12 pemain, 6 pemain inti dan 6 pemain cadangan, sedangkan dalam hoki lapangan tiap tim terdiri dari 16 pemain, 11 pemain inti dan 5 pemain cadangan. Hoki merupakan olahraga beregu, maka perlu adanya kerjasama tim untuk meraih kesuksesan. Akan tetapi dituntut pula adanya kemampuan dari setiap individu pemain dalam menguasai teknik-teknik dasar yang baik, maka seorang permain hoki akan dengan mudah melakukan kerjasama dalam permainan hoki. Menurut Sudrajat dalam Aming dan Entang (2011:13) bahwa "Teknik dasar adalah merupakan keterampilanketerampilan pokok yang harus dikuasai untuk dapat berprestasi tinggi”. Luxbacher (1987) yang dikutip Wibawa (1997) dalam Aming dan Entang (2011:13) menjelaskan "Teknik dasar ialah semua gerakan yang mendasari, dan dengan modal tersebut seseorang dapat bermain dengan baik atau berlatih secara terarah".

Penguasaan terhadap teknik dasar hoki bukanlah hal yang mudah karena olahraga hoki menuntut pemainnya bergerak kian kemari dari satu tempat ketempat yang lain melalui penerapan strategi permainan. Dalam pergerakannya, setiap pemain harus menguasai beberapa teknik dasar permainan hoki, karena jika tidak menguasai teknik-teknik dasar tersebut maka tidak akan tercipta permainan hoki terbaik dan efektif. Selain itu, banyak dasar-dasar permainan hoki yang sangat menunjang pada saat permainan hoki berlangsung, diantaranya adalah penyesuaian posisi tangan saat memegang stik karena ini sangat berpengaruh untuk melakukan teknik dalam permainan hoki, lalu penyesuaian arah passing karena berpengaruh terhadap arah mana yang akan dituju, posisi badan yang sesuai dengan ketentuan agar pada saat melakukan teknik dasar di lakukan dengan baik, lalu berpindah posisi kian kemari, kerja sama dengan tim agar dapat menjalankan strategi permainan yang telah direncanakan, dan berfikir bagaimana menciptakan peluang dan memasukkan bola ke gawang lawan sebanyak mungkin tanpa kemasukkan oleh lawan dan melakukan penyelesaian akhir dengan baik dan terarah. Beberapa teknik yang harus dikuasai diantaranya adalah keterampilan push (mendorong bola), hit (memukul bola), stop (menahan bola), dribble (menggiring bola), flick (mencungkil bola), jab (menjangkau bola), tackle (merampas bola) dan scoop (mengangkat bola). 
Pada saat permainan hoki lapangan berlangsung, teknik dasar yang dominan dilakukan pada saat melakukan passing ataupun shooting yaitu teknik hit, karena teknik ini lebih efektif digunakan dibanding dengan teknik- teknik dasar lainnya, terutama pada saat melakukan passing. Karena dengan menggunakan teknik hit akan mendapatkan hasil passing yang optimal dan terarah. Konsep dari permainan hoki itu sendiri adalah memasukkan bola ke gawang lawan sebanyak mungkin. Untuk menjalankan suatu permainan hoki, teknik yang efektif digunakan pada saat permainan berlangsung yaitu teknik passing, salah satu nya adalah teknik hit. Karena jika di lihat dari konsep gerakannya bahwa teknik hit sangat efektif untuk di gunakan pada saat melakukan passing.

\section{Hit adalah kegiatan} menggerakan bola pada permukaan lapangan dengan melakukan gerakan memukul atau menghentakkan bola. Penguasaan terhadap teknik hit membutuhkan waktu yang relatif lama melalui suatu latihan yang terarah dan terencana serta penerapan prinsip-prinsip latihan yang benar dengan demikian bahwa hit yang dilakukan secara berulang-ulang dan bertambah bebannya akan lebih cepat meningkatkan penguasaan keterampilan tersebut dibandingkan dengan yang tidak berulang-ulang dan bebannya tetap.

Permainan hoki di Indonesia sudah mulai berkembang dan sudah mulai di kenal oleh masyarakat luas, salah satunya di Kabupaten Cianjur. Permainan hoki di Cianjur merupakan suatu cabang olahraga yang selalu ikut serta dalam perhelatan olahraga tingkat Daerah maupun tingkat Nasional. Berbagai prestasi telah dicapai baik tingkat Daerah maupun tingkat Nasional, bahkan sebagian dari atlet di Cianjur ini pernah ikut serta dalam Kejuaraan Nasional. Keberadaan cabang olahraga permainan hoki di Cianjur ini tidak dapat di lepaskan dari kecintaan pelatih dan para alumni hoki Cianjur yang terus ikut berpartisipasi untuk memajukanolahraga hoki di Cianjur.

Bagi atlet remaja untuk melakukan teknik dasar hoki tidaklah mudah dipelajari pada saat latihan, terutama teknik hit tidak dapat dilakukan dengan baik dan benar, terlihat kaku dan tidak terarah pada saat melakukan gerakan atau teknik hit. Menurut Harsono (1988:102) bahwa "Latihan juga bisa dikatakan sebagai sesuatu proses berlatih yang sistematis yang dilakukan secara berulang-ulang yang kian hari jumlah beban latihannya kian 


\section{1| Aziz Amrulloh ${ }^{1}$}

Pengaruh Metode Random Dan Metode Blocked Terhadap

Kemampuan Passing Hit Dalam Permainan Hoki

bertambah". Salah satu fakta yang menunjukan bahwa rendahnya hasil latihan yang dicapai pada permainan hoki adalah sulitnya atlet dalam memenangkan pertandingan dan sulitnya melakukan teknik dasar terutama teknik hit untuk atlet remaja.

\section{Hasil latihan setiap atlet tentu} berbeda dengan atlet yang lainnya. Hal tersebut di pengaruhi oleh cara latihan atlet itu sendiri. Faktor yang menjadi pemasalahan utama yang di hadapi oleh seorang pelatih lebih khususnya adalah penerapan metode pada saat latihan, karena penerapan metode pada saat latihan sangat berpengaruh pada hasil latihan. Menurut sumber yang ditemukan yakni

(http://rangkumanpustaka.blogspot.co.id /2017/04/metode-adalah-cara-

kerja.html) bahwa "Metode adalah cara

kerja yang bersistem untuk memudahkan pelaksanaan suatu kegiatan guna mencapai tujuan yang ditentukan (Depdiknas, 2003:740)".

Berdasarkan definisi di atas, dapat disimpulkan bahwa metode latihan adalah cara yang digunakan dengan tujuan membantu pelatih ataupun atlet dalam mencapai tujuan latihan yang telah direncanakan sebelumnya. Hal ini menegaskan bahwa penggunaan metode latihan yang tepat dan sesuai dengan kebutuhan agar mencapai tujuan yang di harapkan. Untuk mendapat hasil latihan yang baik pada permainan hoki tidak dapat dilakukan dalam satu kali pertemuan saja, akan tetapi dibutuhkan waktu tambahan diluar jam latihan tersebut. Kegiatan ini bertujuan agar atlet dapat meningkatkan keterampilan teknik hit dalam permainan hoki.

Berdasarkan pengamatan yang ada di lapangan, pemilihan metode latihan kiranya belum dapat di pastikan mana yang lebih efektif untuk di terapkan pada saat latihan. Oleh karena itu, penulis akan mencoba menerapkan metode random dan metode blocked.

Metode random adalah teknik dasar itu tidak berpindah-pindah secara kaku antara teknik dasar yang satu dengan teknik dasar yang lain yang di ajarkan dalam satu pertemuan. Seperti di ungkapkan oleh Mahendra dan Ma'mun dalam Maulana (2016:7) bahwa "Metode random menghendaki siswa melakukan sebagai kegiatan latihan dalam suatu waktu, tanpa di pisah-pisahkan oleh jenis keterampilannya". Jadi jelas kita ketahui mereka ini merupakan bentuk latihan dimana setiap kali pertemuan atlet seorang berputar untuk melakukan semua keterampilan dengan cara acak, sehingga atlet tidak pernah melakukan tugas yang sama secara berturut-turut. 
Dalam pelaksanaan perlakuan metode random yang di kemukakan oleh Toto dkk (2014) dalam jurnalnya mengemukakan bahwa metode random berpengaruh secara signifikan terhadap teknik dropshot pada cabang olahraga permainan bulu tangkis.

Sementara itu pola pikir metode blocked yaitu mempelajari satu teknik dalam beberapa kali pertemuan sampai teknik tersebut di kuasai oleh atlet, setelah itu baru pindah ke teknik yang lain. Teknik dasar yang di pelajari sebelumnya tidak dilakukan atau di ajarkan kembali. Seperti yang di kemukakan oleh Mahendra dan Ma'Mun dalam Maulana (2016:6) bahwa "Metode blocked adalah latihan yang di laksanakan dengan mendahulukan satu tugas hingga selesai sebelum berpindah ke tugas lain". Latihan ini banyak di pakai oleh pembina olahraga karena di anggap memungkinkan atlet berlatih secara terfokus, yaitu meraih satu keterampilan berulang-ulang tanpa terganggu kegiatan lain. Cara ini tampaknya masuk akal karena di anggap memungkinkan atlet untuk berkonsentrasi penuh dan menghaluskan gerakannya. Telah di jelaskan juga oleh Toto dkk (2014) dalam jurnalnya mengungkapkan bahwa metode blocked berpengaruh secara signifikan terhadap teknik dropshot dalam cabang olahraga permainan bulu tangkis. Jika melihat perbandingan antara metode random dan metode blocked yang telah dibahas oleh Toto dkk (2014) dalam jurnalnya maka pada pelaksanaan penelitian yang di lakukan pada teknik dropshot cabang olahraga permainan bulu tangkis metode yang paling berpengaruh pada penelitian tersebut adalah metode blocked, karena nilai rata-rata dari metode blocked lebih besar dari pada metode random.

Pernyataan tersebut menarik minat penulis untuk meneliti dan mengkaji kemampuan dan keterampilan dalam memodifikasi latihan untuk atlet remaja Cianjur. Sehingga penelitian ini mengkaji tentang metode random dan metode blocked yang kemudian akan di teliti apakah kedua metode tersebut memberikan kontribusi atau pengaruh yang signifikan terhadap tingkat penguasaan teknik hit dalam permainan hoki pada atlet remaja Cianjur.

\section{B. METODE PENELITIAN}

Penelitian ini merupakan penelitian eksperimen, karena tujuan dari penelitian ini untuk menyelidiki kemungkinan saling hubungan sebab akibat dengan cara mengenakan kepada satu atau lebih kelompok eksperimental satu atau lebih kondisi perlakuan dan memperbandingkan hasilnya dengan satu 
atau lebih kelompok kontrol yang tidak dikenai kondisi perlakuan. Suatu eksperimen akan berhasil jika variabel yang dimanipulasi dan jenis respon yang diharapkan dinyatakan secara jelas dalam suatu hipotesis, juga kondisi-kondisi yang akan dikontrol sudah tepat. Untuk keberhasilan ini, maka setiap eksperimen harus dirancang dulu kemudian di uji coba.

Dalam penelitian ini, penulis mengambil lokasi yang bertempat di Universitas Suryakancana Cianjur, Jawa Barat.

Dalam penelitian ini pengumpulan data diambil dari hasil tes keterampilan hit. Penelitian ini dilaksanakan selama 18 kali pertemuan, yang diawali dengan melakukan tes awal (pretest) 1 kali pertemuan, 16 kali pertemuan diberikan programlatihan dan pertemuan akhir diadakan tes akhir (posttest). Adapun kegiatannya adalah sebagai berikut:

1. Tes Awal (pretest)

Pelaksanaan tes awal sampai selesai bertempat di stadion mini Universitas Suryakancana Cianjur. Sebelum pelaksanaan tes, siswa disiapkan, diabsen dan diberi penjelasan tentang pelaksanaan tes. Selanjutnya melakukan pemanasan untuk menghindari hal-hal yang tidak diingiinkan.
2. Pemberian Perlakuan (treatment) Pemberian perlakuan (treatment) pada eksperimen ini dilaksanakan 18 kali pertemuan, dengan 1 kali pertemuan untuk tes awal, dan 1 kali pertemuan untuk tes akhir. Latihan ini dilakukan selama 4 kali dalam seminggu yaitu selasa, kamis, sabtu, minggu.

\section{a. Pemanasan (warming up)}

Sebelum melakukan latihan inti, atlet diberikan pemanasan terlebih dahulu untuk menaikkan suhu tubuh dan menghindari resiko terjadinya cedera otot dan sendi. Pemanasan ini meliputi, pemanasan statis, kemudian pemanasan dinamis, lalu jogging 5 keliling lapangan.

b. Latihan inti

Setelah melakukan pemanasan, langsung masuk pada latihan inti, yaitu pemberian metode latihan pada 2 kelompok berbeda yaitu kelompok A diberikan perlakuan metode random, lalu kelompok B diberikan perlakuan metode blocked.

c. Pendinginan (cooling down)

Setelah pemberian treatment selesai, maka atlet melakukan pendinginan dengan melakukan PNF.

3. Tes Akhir (Posttest) 
Tes akhir yang digunakan dalam penelitian ini sama dengan yang dilakukan pada tes awal yaitu tes keterampilan hit, dengan tujuan untuk mengetahui hasil yang dicapai oleh tiaptiap atlet dari masing-masing kelompok setelah diberikan treatment. Hasil tes akhir dicatat untuk mengetahui pengaruh dari kedua bentuk latihan tersebut dan mana yang lebih baik hasilnya.

Data yang diperoleh dari tes awal, tes akhir, perlu diolah. Dengan tujuan untuk melihat tingkat keberhasilan dari penelitian serta menjawab rumusanrumusan masalah yang telah dibuat. Adapun teknik pengolahan data ini terbagi atas pengolahan data kuantitatif. Untuk pengolahan data kuantitatif dilakukan dengan sistem SPSS. Dalam pengolahan data ini analisis yang dilakukan adalah analisis dari data pretest dan data posttest.

\section{HASIL PENELITIAN DAN PEMBAHASAN}

\section{Hasil Penelitian}

Analisis data hasil kemampuan awal (pretest). Pretest dilakukan sebelum atlet diberikan perlakuan. Kemampuan awal yang diukur adalah kemampuan awal atlet dalam latihan passing hit permainan hoki.

Analisis data pretest yang dilakukan adalah uji normalitas data, uji homogenitas data, dan uji kesamaan dua rata-rata (Uji-T). Adapun hasil pengujiannya sebagai berikut:

\section{Tabel 1}

Uji Normalitas Data Pretest

\begin{tabular}{|c|c|c|}
\hline Kelompok & Sig. & Ket \\
\hline Random & .692 & $\mathrm{H}_{0}$ Diterima \\
\hline Blocked & .771 & $\mathrm{H}_{0}$ Diterima \\
\hline
\end{tabular}

Tabel 2

Hasil Uji Kesamaan Dua Rata-Rata

\begin{tabular}{|c|c|}
\hline \multicolumn{2}{|c|}{ Data Pretest } \\
\hline Sig (2-tailed) & ket \\
\hline 0.963 & $\mathrm{H}_{0}$ diterima \\
\hline
\end{tabular}

Berdasarkan tabel 2 menunjukkan bahwa nilai Sig (2-tailed) sebesar 0.963 , karena nilai signifikansi lebih besar dari 0.05 , maka $\mathrm{H}_{0}$ diterima. Berarti kedua kelas memiliki nilaipretest yang setara. Sehingga dapat diambil kesimpulan bahwa kemampuan awal passing hit antara kedua kelompok latihan yaitu setara.

Analisis data hasil kemampuan akhir passing hit permainan hoki (posttest). Posttest dilakukan sesudah atlet diberikan perlakuan (treatment). 
Menggunakan metode random dan metode blocked. Kemampuan akhir diukur dari tes keterampilan hit.

Analisis data posttest yang dilakukan adalah uji normalitas data, uji homogenitas data, lalu uji kesamaan dua rata-rata (Uji-T). Adapun hasil pengujiannya adalah sebagai berikut:

Tabel 3

\section{Hasil Uji Normalitas Posttest}

\begin{tabular}{|c|c|c|}
\hline kelompok & Sig & Ket \\
\hline Random & .868 & $\mathrm{H}_{0}$ diterima \\
\hline Blocked & .801 & $\mathrm{H}_{0}$ diterima \\
\hline
\end{tabular}

Tabel 4

\section{Hasil uji kesamaan dua rata-rata}

Posttest

\begin{tabular}{|c|c|}
\hline \multicolumn{2}{|c|}{ Data Posttest } \\
\hline Sig (2-tailed) & Ket \\
\hline .044 & $\mathrm{H}_{0}$ diterima \\
\hline
\end{tabular}

Berdasarkan tabel 4 diperoleh nilai Sig (2-tailed) sebesar 0.044, lebih dari 0.05 maka $\mathrm{H}_{0}$ diterima. Berarti, kedua kelas memiliki nilai posttest yang setara. Sehingga dapat diambil kesimpulan bahwa kemampuan tes akhir antara metode random dan metode blocked adalah setara.

\section{Pembahasan}

Setelah dilakukan penelitian tentang permasalahan yang dihadapi dan dibahas mulai dari awal sampai dengan ditariknya suatu kesimpulan sementara, bahwa untuk dapat meningkatkan kemampuan passing hit dalam permainan hoki, dengan penerapan metode latihan random dan metode latihan blocked yang dilakukan ternyata kedua metode latihan tersebut memberikan makna yang berarti terhadap kemampuan passing hit. Kedua metode tersebut memberikan pengaruh yang berbeda. Namun jika dilihat dari nilai rata-ratanya, maka metode blocked lebih berpengaruh terhadap kemampuan passing hit dalam permainan hoki dari pada metode random, hal itu dilihat dari nilai rata-rata dari tes akhir kemampuan passing hit pada kedua kelompok yaitu untuk metode random sebesar 8.07 dan untuk metode blocked sebesar 10.47.

Hasil pengolahan data secara statistik dan pembahasan hasil penelitian membuktikan bahwa penelitian ini merupakan awal dari langkah selanjutnya dalam upaya penerapan metode latihan yang baik diterapkan pada saat proses 
latihan berlangsung khususnya dalam latihan passing hit permainan hoki atlet remaja Kabupaten Cianjur.

\section{KESIMPULAN}

Berdasarkan hasil analisis data, maka dapat diambil kesimpulan sebagai berikut:

1. Terdapat pengaruh yang signifikan metode random terhadap kemampuan passing hit dalam permainan hoki atlet remaja Cianjur.

2. Terdapat pengaruh yang signifikan metode blocked terhadap kemampuan passing hit dalam permainan hoki atlet remaja Cianjur.

3. Metode blocked lebih signifikan pengaruhnya dibandingkan metode random terhadap kemampuan passing hit dalam permainan hoki atlet remaja Cianjur.

\section{DAFTAR PUSTAKA}

Anders, Elizabeth., dan Myers, Sue. 1999. Field Hockey Steps To

Success. USA: Human Kinetics

Harsono. 1988. Coaching dan Aspek-

$\begin{array}{lrr}\text { Aspek Psikologis } & \text { Dalam } \\ \text { Coaching. Jakarta: } & \text { Tambak } \\ \text { Kusuma } & & \end{array}$

Maulana. 2016. Perbandingan Metode Random dan Metode Blocked Terhadap Hasil Belajar Shooting Free Throw Dalam Permainan Bola Basket Pada Siswa Kelas X SMA NEGERI 1 CIBADAK. Cianjur: Universitas Suryakancana.

Nasution. 2014. Metode Research. Jakarta: Bumi Aksara.

Priyatno, D. 2014. SPSS 22 Pengolahan Data Terpraktis. Yogyakarta: ANDI OFFSET

Rahmani, M. 2014. Buku Super Lengkap Olahraga. Jakarta: Dunia Cerdas.

Sugiyono. 2017. Metode Penelitian Kuantitatif Kualitatif dan $R \& D$. Bandung: Alfabeta.

Supriatna, A. Hermanu, E. 2011. Modul Pelatihan Cabang Olahraga Hoki. Bandung: Universitas Pendidikan Indonesia.

Rustiana, W. 2013. Perbandingan Pembelajaran Pendekatan Taktis Dan Pendekatan Teknis Terhadap Hasil Belajar Push dan Hit Siswa Dalam Permainan Hoki. Bandung: Universitas Pendidikan Indonesia. 
47| Aziz Amrulloh ${ }^{1}$

Pengaruh Metode Random Dan Metode Blocked Terhadap

Kemampuan Passing Hit Dalam Permainan Hoki

Wahyudi, R. 2015. Implementasi Latihan

Terpusat (Blocked Practice)

Dengan Latihan Acak (Random

Pracite) Untuk Meningkatkan

Keterampilan Dasar Pada

Permainan Sepakbola. Bandung:

Universitas Pendidikan

Indonesia.

http://file.upi.edu/Direktori/FPOK/JUR.

_PEND._OLAHRAGA/196308

241989031AGUS_MAHENDR

A/Modul_Perkembangan_\%26_

Belajar_Motorik_Agus_Mahend

ra/Modul_12-

Persiapan_Pembelajaran.pdf

https://journal.unnes.ac.id/sju/index.php/ jssf/article/view/6215

http://rangkumanpustaka.blogspot.co

.id/2017/04/metode-adalah-

cara-kerja.html

https://www.mushlihin.com/2013/11/

penelitian/memahamidefinisi-

opesarionaldalampenelitian.p

hp 